\title{
Invited correspondence on 'Fissureless fissure-last video-assisted thoracoscopic lobectomy for all lung lobes: a better alternative to decrease the incidence of prolonged air leak?'
}

\author{
Davor Stamenovic
}

Department of Thoracic Surgery, St Vincentius Kliniken D, 76137 Karlsruhe, Germany

Correspondence to: Davor Stamenovic. Department of Thoracic Surgery, St Vincentius Kliniken D, 76137 Karlsruhe, Germany.

Email: davor.stamenovic@vincentius-ka.de.

Provenance: This is an invited article commissioned by the Section Editor Shuangiiang Li (Department of Thoracic Surgery and West China Medical Center, West China Hospital, Sichuan University, Chengdu, China).

Response to: Igai H, Kamiyoshihara M, Yoshikawa R, et al. Invited editorial on "Fissureless fissurelast video-assisted thoracoscopic lobectomy for all lung lobes: a better alternative to decrease the incidence of prolonged air leak?”. J Thorac Dis 2018;10:S2183-5.

Voltolini L, Bongiolatti S, Gonfiotti A. Fissureless fissure-last video assisted thoracoscopic lobectomy: always? never? sometimes. J Thorac Dis 2018;10:S3135-7.

Refai M. Editorial comment on 'Fissureless fissure-last video-assisted thoracoscopic lobectomy for all lung lobes: a better alternative to decrease the incidence of prolonged air leak?'. J Thorac Dis 2018;10:S3198-9.

Submitted Sep 12, 2018. Accepted for publication Sep 21, 2018.

doi: $10.21037 /$ jtd.2018.11.38

View this article at: http://dx.doi.org/10.21037/jtd.2018.11.38

At the time I was initiating this study (1), I wasn't aware of other studies on fissureless fissure-last technique. More precisely, as I start operating with this technique, especially for non-upper lobes, I was trying to solve a basic technical problem that I was facing from time to time, thinking I might have been the first to do so.

Then I realized there were few others, who explored this topic before me. Gomez-Caro did it in open fashion surgery in 2007 , in a randomized prospective study, by delivering almost a flawless surgical research paper (2). But Nomori did it not only before him, in 2002, but also by means of thoracoscopic, minimally invasive surgery (3).

However, there were few differences in surgical technique, especially for the left lower lobe. It is not, to the present day, clear to me, how they had taken care of the pulmonary artery before they divided the bronchus and without stapling the fissure (being a fissure-last technique).

Our study had many flaws; being not randomized and having three different surgeons with different level of skills and capability to perform all the resections are only the two of them. Still, it was the first original surgical research paper ever emphasizing the importance of fissureless fissure-last technique by means of minimally invasive thoracoscopic surgery in reducing postoperative air leak, hence overall complications and length of hospital stay. It not only described the technique, but also referring videos already being published on CTSNet, thus allowing synthesis of written words and movies ("a picture is worth a thousand words").

Soon after this publication I decided to publish a singlesurgeon experience with non-upper lobe fissure-last resections (4), realizing that upper-lobe resections were already accepted in surgical community, mainly due to their relative easiness, but may be also due to publications oriented solely on one, the right upper lobe $(5,6)$. Left upper lobe is, although maybe slightly more challenging than the right, can also be performed easily with a bit of experience. Non-upper lobes were more challenging. I had witnessed complete disorientation at very experienced hands a few times, due to "awkward" anatomy in the lower lobes. I assumed that the adoption of fissureless fissure-last technique for the lower lobes might take time. I thought that dedicated publications on this issue along with some "show-how" videos might speed up an acceptance. Seeing some several recent videos from our thoracic surgery 
community, I cannot deny my satisfaction.

When I decided to start performing uniportal VATS nearly three years ago, I did it autodidactically, having enough experience in "conventional" minimally invasive approach for lobectomy. It has been going very well, from the very beginning. I have applied fissure-last technique always, whenever I needed to, realizing that depending on the anatomy, fissure-last is still frequently, if not always, possible.

However in a lot of cases, mostly in non-upper lobes, fissureless (but not necessarily fissure-last) may not only be sufficient, but also more suitable; in other words, I do not insist exactly on fissure-last even when I keep on performing fissureless (avoiding dissection of the fissure). For instance, when I do surgery in the left lower lobe, I may divide the lower vein and the left lower bronchus (removing or temporarily moving the lymph nodes aside) exposing exactly the basal segmental artery. Next step varies: instead of going for encircling of the artery (either basal segmental, superior segmental or both), it may be easier and safer to divide the parenchymal bridge between the two lobes just up to (or frequently even above) the artery. Thus it becomes easier to encompass the basal segmental artery. Besides it allows easier identification of the lingular artery, which should be preserved. On other occasions a fissure-last resection seems to be proper.

In my opinion fissureless resections, not necessarily fissure-last, should be a priority always when the pulmonary artery is presumably not to be easily exposed via fissure (7), regardless if you perform one or multi-port thoracoscopic resections. This technique is both learnable and teachable.

A multi centric prospective randomized study may be warranted to give the final answer regarding the importance of this technique when applied by means of minimally invasive approach.

Cite this article as: Stamenovic D. Invited correspondence on 'Fissureless fissure-last video-assisted thoracoscopic lobectomy for all lung lobes: a better alternative to decrease the incidence of prolonged air leak?'. J Thorac Dis 2018;10(12):E810-E811. doi: $10.21037 /$ jtd.2018.11.38

\section{Acknowledgements}

None.

\section{Footnote}

Conflicts of Interest: The author has no conflicts of interest to declare.

\section{References}

1. Stamenovic D, Bostanci K, Messerschmidt A, et al. Fissureless fissure-last video-assisted thoracoscopic lobectomy for all lung lobes: a better alternative to decrease the incidence of prolonged air leak? Eur J Cardiothorac Surg 2016;50:118-23.

2. Gómez-Caro A, Calvo MJ, Lanzas JT, et al. The approach of fused fissures with fissureless technique decreases the incidence of persistent air leak after lobectomy. Eur J Cardiothorac Surg 2007;31:203-8.

3. Nomori H, Ohtsuka T, Horio H, et al. Thoracoscopic lobectomy for lung cancer with a largely fused fissure. Chest 2003;123:619-22.

4. Stamenovic D, Bostanci K, Messerschmidt A, et al. Fissure-last video-assisted thoracoscopic lobectomy for 'non-upper' lobes. ANZ J Surg 2017;87:1021-5.

5. Refai M, Brunelli A, Salati M, et al. Efficacy of anterior fissureless technique for right upper lobectomies: a casematched analysis. Eur J Cardiothorac Surg 2011;39:1043-6.

6. Ng T, Ryder BA, Machan JT, et al. Decreasing the incidence of prolonged air leak after right upper lobectomy with the anterior fissureless technique. J Thorac Cardiovasc Surg 2010;139:1007-11.

7. Craig SR, Walker WS. A proposed anatomical classification of the pulmonary fissures. J R Coll Surg Edinb 1997;42:233-4. 